\title{
A quasi in situ TEM grid reactor for decoupling catalytic gas phase reactions and analysis
}

Liudmyla Masliuk ${ }^{1, \sharp}$, Manfred Swoboda $^{1}$, Gerardo Algara-Siller ${ }^{1}$, Robert Schlögl ${ }^{1,2}$, Thomas Lunkenbein,, ,***

${ }^{1}$ Department of Inorganic Chemistry, Fritz-Haber-Institut der Max-Planck-Gesellschaft, Berlin, Germany

${ }^{2}$ Max-Planck-Institute of Chemical Energy Conversion, Mülheim, Germany

*E-mail: lunkenbein@,fhi-berlin.mpg.de

ABSTRACT: We present a versatile grid reactor setup for transmission electron microscopy (TEM), which allows to track catalytic conversion on TEM amounts of sample. It is based on the concept of decoupling catalytic gas-phase reactions from the structural analysis of identical particles. The system has superior properties in terms of image resolution and long-term measurements compared to conventional in situ TEM analysis. It allows for monitoring catalytic conversions on a TEM grid by proton-transfer reaction mass spectrometry and then characterize it by TEM. In addition, identical location imaging benefits from a secure transfer of the sample between TEM and the reactor system by vacuum transfer holders. Using $\mathrm{Pt}$ and $\mathrm{Cu} / \mathrm{ZnO} / \mathrm{Al}_{2} \mathrm{O}_{3}$ as an example we show that structural changes of identical particles or areas of a Pt foil before and after reactive experiments can be tracked. During catalytic testing the samples are exposed to homogeneous reaction conditions. The concept minimizes electron-sample and electron-atmosphere interactions and can prospectively be considered as complementary tool to in situ TEM analysis. 
Keywords: Identical location imaging, heterogeneous catalysis, conversion, local characterization, nanoparticles, polycrystalline foil.

\section{INTRODUCTION.}

Heterogeneous catalysis is considered to be one of the most promising technologies for prospective energy storage.[1-2] To tailor catalyst systems for such specific applications the evolution of the active phases under a given chemical potential and their impact on catalytic conversion has to be understood. A pre-requisite for harvesting details on relevant structural dynamics is the investigation of catalytic systems at relevant reaction conditions (i.e. gaseous environment, temperature, pressure), which also includes the detection of catalytic conversion.[3] These requirements can be met by spectroscopic and electron microscopic techniques.[4-8] Gas-phase induced changes can for instance be tracked by in situ spectroscopic analysis, such as infra-red (IR), Raman or X-ray photoelectron spectroscopy (XPS).[9-11] In combination with theoretical modelling, these techniques can deliver integral information of compositional alterations, surface species and oxidation states.[12-13] Those analytical methods, however, average over the whole sample and, thus, local alterations and/or important defects, and surface states may be overlooked.

Local geometric and electronic information can be obtained by ex situ and in situ transmission electron microscopy (TEM).[14-19] In ex situ TEM experiments, samples are analyzed after removal from the catalytic reactor using the optimal TEM resolution and are compared with the structure of assynthesized samples. This ex situ approach neglects the position of the investigated catalyst particles in the reactor, whose surface structures may be biased by location-dependent modifications of the gas composition and/or temperature gradients.[20-21] Due to these inhomogeneities, extrapolation of the 
observed local surface structure to the whole catalyst system may not reflect the state of the complete catalyst batch inside the reactor. In addition, during exposure to ambient air, hydration phenomena may occur that alter the structure of the surface.

The concept of in situ TEM is long-rooted in electron microscopic science.[22-24] Currently, two kinds of in situ TEM set-ups are commonly used: (1) environmental and (2) gas-cell holders.[7, 16, 19, 25-26] In the former set-up, gas is introduced directly into the octagon region of the TEM. Owing to electron scattering events at the gaseous atmosphere and vacuum requirements for a TEM to work the pressure of the gas is limited to approximately 10 mbar. For the latter set-up, the sample is sandwiched between two microelectromechanical system (MEMS) chips, which are equipped with electron transparent windows. Those systems can be applied in a broad fields of research, which ranges from heterogeneous catalysis, electrocatalysis, to biochemistry, inorganic chemistry and engineering.[7, 27-32] In situ TEM delivers valuable insights into sample-gas and sample-liquid interactions, or mechanical stabilities. Gas cell holders can be operated at ambient pressure. However, data interpretation of in situ experiments may be limited by lower resolution and electron-matter interactions.

To link the advantages of ex situ with in situ TEM analysis, the quasi in situ approach was developed.[33-34] Quasi in situ TEM is defined as the repeated exposure of the same specific sample to relevant as well as homogeneous reaction conditions outside the TEM and characterization in the TEM.[35] The concept of quasi in situ TEM has already been exploited, for instance, in the electrochemical degradation of Pt/C systems and in corrosion studies of AA2024-T3 alloys.[35-36] Changes of the particles were monitored by identical location imaging (ILI).[36-37] In addition, a controlled environment TEM holder has been recently introduced, which allows for sample transfer between different analytical tools under the same environment.[34] 
Here, we present a quasi in situ setup as general tool to study catalytic gas-phase reactions on a TEM grid under relevant and homogeneous conditions. The reactor setup decouples catalysis and analysis. The system operates at elevated temperatures and allows the detection of catalytic conversion. A sophisticated transfer procedure is established to transport the TEM grid without exposure to ambient air. The proof of working principle is demonstrated here with $\mathrm{CO}$ oxidation over different Pt compounds and the reductive activation of $\mathrm{Cu} / \mathrm{ZnO} / \mathrm{Al}_{2} \mathrm{O}_{3}$ catalyst for methanol synthesis.

\section{MATERIALS AND METHODS.}

Figure 1a shows a photograph of the quasi in situ TEM grid reactor. It is composed of three CF-16 parts that are sealed by inert $\mathrm{Au}$ coated $\mathrm{Cu}$ gaskets and can be operated at ambient pressure. The reactor was passivated either by silylation (Silkotec) or Au coating. Technical drawings of the top part of the TEM grid reactor at different orientations are presented in Figure $1 \mathrm{~b}$. The middle CF-16 flange exhibits a sealable feed-through for one thermocouple (type K). The thermocouple is mounted in an electrically conductive Si-infiltrated $\mathrm{SiC}(\mathrm{Si} / \mathrm{SiC})$ sample holder and touches the bottom of the TEM grid (Figure 1c). The TEM grid is fixed in the cavity of the $\mathrm{Si} / \mathrm{SiC}$ sample holder by $\mathrm{Au}$ coated $\mathrm{Cu}$ clamp rings (Figure 1c). The $\mathrm{Si} / \mathrm{SiC}$ sample holder is screwed on an $\mathrm{Au}$ coated stainless steel holder, which is placed on top of a CF-16 fused-silica window (MDC Vacuum Ltd.). The fused-silica window exhibits high transparency for red and infrared (IR) light (Figure 1c). Passive heating of the TEM grid is accomplished by the $\mathrm{Si} / \mathrm{SiC}$ holder, which is exposed to an IR laser light ( $\lambda=800 \mathrm{~nm}$, Limo) from the bottom. The laser light ensures temperatures up to $500^{\circ} \mathrm{C}$. Owing to the small sample quantity $(<60 \mu \mathrm{g})$ and high power of the laser a fast heating and rapid cooling (quenching) can be realized. As shown in Figure 1a the gas in- and outlet are composed of Swagelok tubes and nuts (1/8", 1/16"). The reactor is connected via Swagelok quick connectors of the QM series to the gas feeding line. Figure 2 depicts a schematic drawing of the TEM grid reactor in which the gas flow is indicated. Additional Reynolds 
number calculations (Figure $\mathrm{S} 1$, assumptions: flow $=20 \mathrm{ml} / \mathrm{min} ; \mathrm{p}=1 \mathrm{bar} ; \mathrm{T}=25^{\circ} \mathrm{C} ; 200^{\circ} \mathrm{C}$, medium: air) imply a laminar gas flow to the sample. This indicates homogeneous reaction conditions over the entire sample.
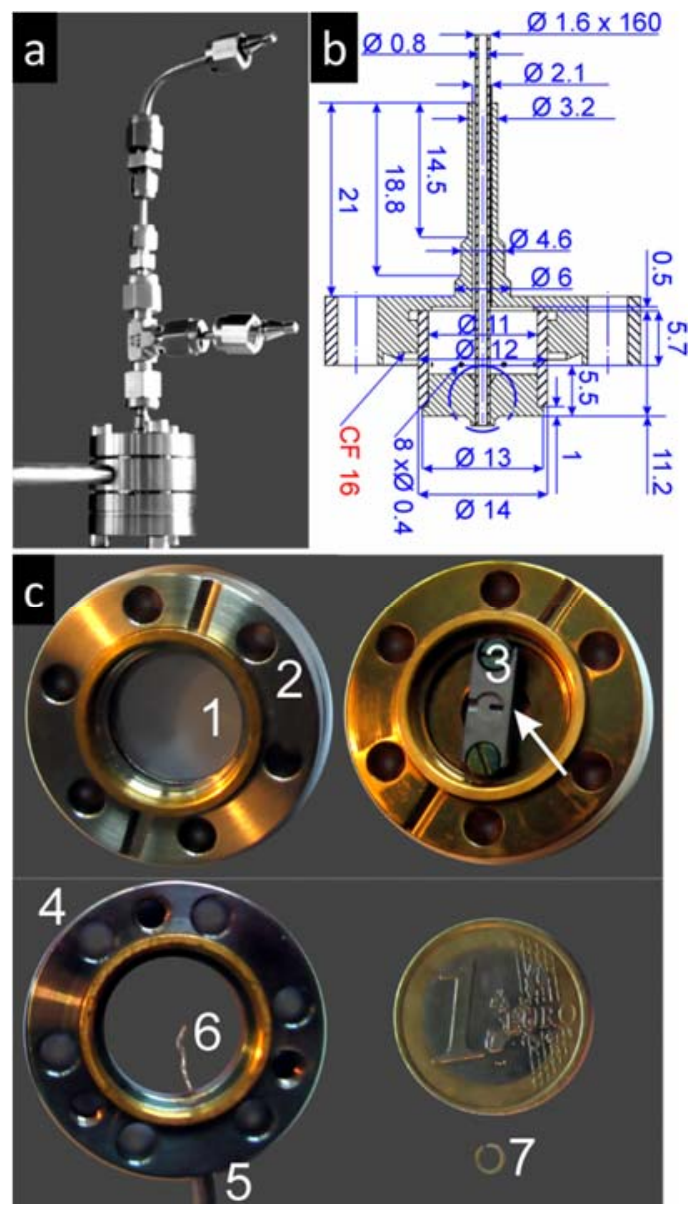

Figure 1. The quasi in situ TEM grid reactor. (a) Photograph of the TEM grid reactor. (b) Technical drawing of the side view of the gas in- and outlet of the top part of the TEM grid reactor. Dimensions are given in mm. (c) Detailed photographs of the bottom and center flanges of the TEM grid reactor: (1) Au coated CF-16 flange with fused silica window, (2) Au coated $\mathrm{Cu}$ gasket, (3) $\mathrm{Si} / \mathrm{SiC}$ crucible with cavity for a TEM grid and slot for the thermocouple (white arrow) mounted on an annular Au coated stainless steel holding device, which is placed on top of the fused silica window sample, (4) modified 
center CF-16 flange, (5) feedthrough for thermocouple, (6) thermocouple, and (7) clamp ring for fixing the TEM grid in the $\mathrm{Si} / \mathrm{SiC}$ crucible.

At the outlet, a proton-transfer mass spectrometer (PTR-MS, Ionicon) is placed to detect the conversion of the catalytic reaction. TEM images were recorded on a Cs corrected FEI Titan 80-300 at an acceleration voltage of $300 \mathrm{kV}$ and on a double corrected JEOL ARM 200F at an acceleration voltage of $200 \mathrm{kV}$. GATAN vacuum transfer holders (single tilt 648 and VTST4006) were used for sample transfer. Energy dispersive X-ray (EDX) spectrometry was recorded on a Philipps CM FEG 200 equipped with a Genesis 4000 EDX detector.

$250 \mu \mathrm{m}$ thick Pt foils (99.9999) were purchased from Goodfellow. A round, self-supporting sample with $3 \mathrm{~mm}$ diameter, which matches the diameter of the TEM grid holder, was stamped out the foil before catalytic testing. The center of the foil was thinned by mechanical grinding to obtain electron transparent parts. Pt nanoparticles were prepared by vapor deposition onto silica coated $\mathrm{Si}_{3} \mathrm{~N}_{4}$ windows (15 nm, Norcada). $\mathrm{Cu} / \mathrm{ZnO} / \mathrm{Al}_{2} \mathrm{O}_{3}$ catalysts were synthesized as reported previously.[38] If applicable prior to TEM imaging the Pt samples were plasma cleaned in $\mathrm{O}_{2}$ or $\mathrm{O}_{2}$-Ar plasma up to $30 \mathrm{~s}$. In addition, the Pt samples and the reactor were pre-treated before the catalytic reaction in a $\mathrm{N}_{2}$ flow at reaction temperature until the PTR-TOF signal was stabilized at the background level in order to identify and remove possible contamination. 


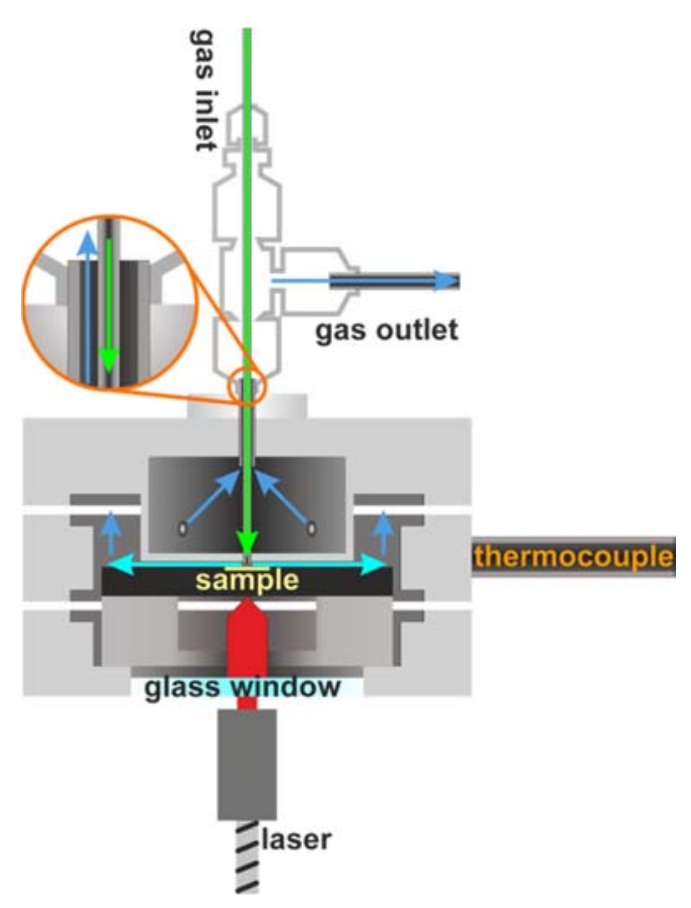

Figure 2. Schematic drawing of the interior of the assembled TEM grid reactor and indicated gas flow directions. The gas flows over the sample (green arrow), reacts and migrates to the sides (cyan arrows), moves to the top and can penetrate the chamber through the holes (blue arrows). A larger tube that hosts the smaller inlet tube allows the gas to leave the reactor (inset).

\section{RESULTS.}

\section{Conversion Detection}

For catalytic reactions, which happen on a TEM grid, very low conversions can be expected. To overcome this detection limitation a PTR-MS is used. The PTR-MS is very sensitive and allows the detection of volatile species in the low parts per trillion (pptv) regime.[39-40] The absence of electron ionization is the key for its selectivity. Ionization is usually accompanied by a high-energy impact on the analyte, which subsequently leads to undesired fragmentation that lowers the sensitivity. In PTRMS, the ionization is initiated by energetic soft proton transfer from in situ generated hydronium cations to the analyte. A prerequisite for the detection of the volatile molecule is usually a higher proton affinity 
(PA) of the analyte compared to water $(\mathrm{PA}=7.2 \mathrm{eV})$. However, if gases have to be detected that have a lower proton affinity than water, for instance $\mathrm{CO}_{2}(\mathrm{PA}=5.6 \mathrm{eV})$, an additional energy of $1.6 \mathrm{eV}$ can be applied to shift the reaction towards protonated $\mathrm{CO}_{2}\left(\mathrm{CO}_{2} \mathrm{H}^{+}\right)$. The energetic boost can be obtained by fine tuning the voltages at the end of the drift tube.[41] Note, the PA of $\mathrm{CO}(\mathrm{PA}=6.2 \mathrm{eV})$ is higher than the one for $\mathrm{CO}_{2}$.

\section{Temperature Calibration and Wall Reactivity}

The temperature of the TEM grid reactor was calibrated by thermal decomposition of carbonates (Figure 3a). Lead carbonate $\left(\mathrm{PbCO}_{3}\right)$ was used as carbonate source. $\mathrm{PbCO}_{3}$ decomposes in three distinct steps at temperatures below $400^{\circ} \mathrm{C}$ to $\mathrm{PbO}$.[42] These three steps which arise at $248^{\circ} \mathrm{C}, 293^{\circ} \mathrm{C}$, and $343^{\circ} \mathrm{C}$ can also be observed in thermogravimetric reference measurements (TGA, Ar atmosphere, Figure 3a, top) and their corresponding $1^{\text {st }}$ derivative (Figure $3 \mathrm{a}$, middle). During the thermal decomposition of $\mathrm{PbCO}_{3}$ using the TEM grid reactor setup the $\mathrm{CO}_{2}$ traces of the PTR-MS (Figure 3a, bottom) a shoulder at lower temperatures and two sharp peaks at $310^{\circ} \mathrm{C}$ and $360^{\circ} \mathrm{C}$, which can be correlated to the $1^{\text {st }}$ derivative of the TGA signal. The differences in the peak shape can be attributed to the different reaction geometries of the TGA setup and the TEM grid reactor. The shift to higher temperatures in the PTR-MS $\mathrm{CO}_{2}$ traces may be attributed to the cooling of the low amount of sample by a relatively high flow of $\mathrm{N}_{2}$ and/or an increased response time of the PTR-MS as a consequence of a large reactor-MS distance. 

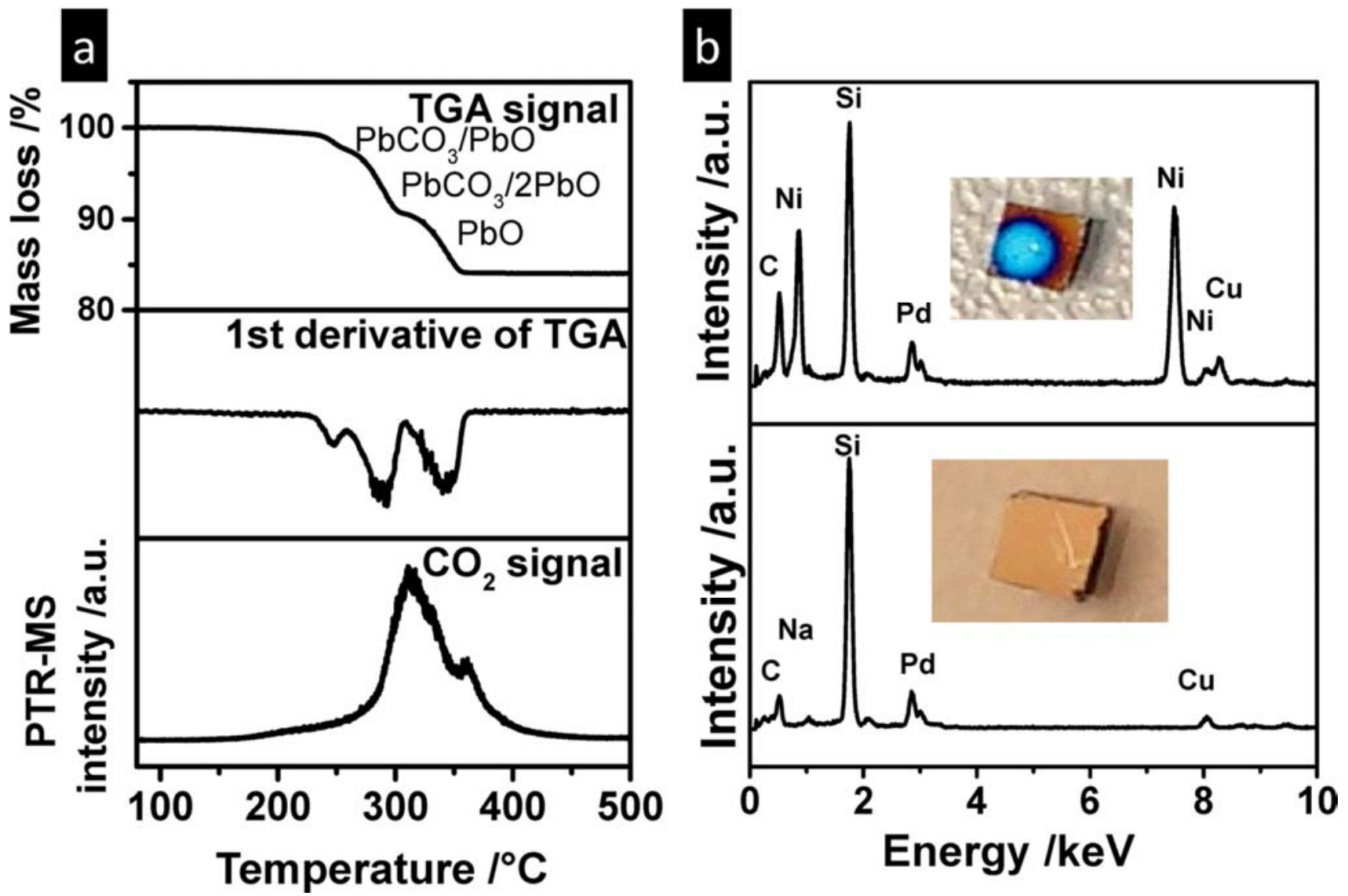

Figure 3. (a) Temperature calibration of the TEM grid reactor: TGA signal (top), 1st derivative of the TGA signal (middle) and PTR-MS signal (bottom) as obtained from the thermal decomposition of $\mathrm{PbCO}_{3}$ in inert atmosphere recorded with a heating rate of $10^{\circ} \mathrm{C} / \mathrm{min}$. (b) EDX measurements of $\mathrm{Pd} @ \mathrm{Si}$ wavers, which were placed in the TEM grid reactor during $\mathrm{CO}$ oxidation: (top) before and (bottom) after inertization. The $\mathrm{Cu}$ signal can be attributed to the TEM holder.

\section{Catalytic Test Reaction}

$\mathrm{CO}$ oxidation was chosen as a catalytic test reaction since this reaction requires very clean and inert reactors. This is of particular importance due to the low amount of catalysts, which is usually deposited on the TEM grid. The presence of hydrocarbons, dust impurities and/or reactive walls can increase the $\mathrm{CO}_{2}$ signal. In addition, $\mathrm{CO}$ forms volatile carbonyl species with $\mathrm{Ni}$ (Mond Process)[43] and $\mathrm{Fe}$ 
(Carbonyl Iron) even at room temperature.[44] These volatile carbonyls decompose at temperatures above $200^{\circ} \mathrm{C}[45-46]$ at the sample as evidenced by the blue interference pattern and the energy dispersive X-ray spectra, which are presented in Figure 3b, top. To avoid the formation and deposition of volatile Ni and/or Fe carbonyls a carbonyl trap filled with SiC particles was placed in front of the reactor and heated to $250^{\circ} \mathrm{C}$. After the carbonyl trap $\mathrm{Cu}$ tubes were used and all reactive stainless steel parts, including the thermocouple, inside the reactor were coated with a macroscopic Au layer, which is inactive in the $\mathrm{CO}$ oxidation.[47] After this passivation step, no Ni and/or Fe species were identified on the sample as indicated by EDX measurements (Figure 3b, bottom).

\section{Catalytic Oscillations}

Figure 4a shows PTR-MS CO and $\mathrm{CO}_{2}$ traces of a polycrystalline Pt foil (diameter: $3 \mathrm{~mm}$ ), which was exposed to $\mathrm{CO}$ oxidation conditions $\left(\mathrm{CO}: \mathrm{O}_{2}=1: 5\right)$ in the TEM grid reactor. The reaction of $\mathrm{CO}$ and $\mathrm{O}_{2}$ over Pt foils has a long history in heterogeneous catalysis research[48] and was tracked in the temperature regime up to $450^{\circ} \mathrm{C}$ using heating and cooling rates of 10 and $2^{\circ} \mathrm{C} / \mathrm{min}$, respectively. Above $250^{\circ} \mathrm{C}$ the formation of $\mathrm{CO}_{2}$ was detected, while the $\mathrm{CO}$ signal decreased. The relatively high onset temperature might be attributed to the low sensitivity of the PTR-MS for $\mathrm{CO}_{2}$ (approx. $100 \mathrm{ppm}$ ). In addition, a high weight hourly space velocity can reduce the conversion which may also contribute to the higher onset temperature. In fact, higher onset temperatures are not surprising for TEM amounts of sample and have also been reported previously for TEM nanoreactors.[7] During fast heating $\left(10^{\circ} \mathrm{C} / \mathrm{min}\right)$ weak oscillations were observed in the temperature regime between $290^{\circ} \mathrm{C}$ and $310^{\circ} \mathrm{C}$ (Figure $4 \mathrm{~b})$. Upon slow cooling $\left(2^{\circ} \mathrm{C} / \mathrm{min}\right)$ strong oscillations were detected in the temperature interval between $320^{\circ} \mathrm{C}$ and $290^{\circ} \mathrm{C}$ (Figure 4c). The periodicity and the amplitude of the oscillations increase with a decrease of the temperature which is in line with previous results.[49-50] As opposed to previous measurements[51], an exponential correlation of the oscillation periodicity and temperature was found 
(Figure 4d). The higher oscillations temperature compared to previous studies on polycrystalline Pt foils may stem from the relatively high CO partial pressure. The increase in the CO partial pressure shifts the oscillatory region to higher temperatures.[50] Such oscillations are common for platinoids in $\mathrm{CO}$ oxidation and may originate at pressures above $1 \mathrm{mbar}$ from an interchanging between metallic and oxidic surfaces states.[52] CO exhibits high adsorption energies for metal surfaces, which generates smoothed surfaces states. After conversion of $\mathrm{CO}$ to $\mathrm{CO}_{2}$, the $\mathrm{CO}$ partial pressure decreases and the excess oxygen initiates the formation of rough oxidic surfaces. This may enhance the reaction velocity. Roughening, however, energetically favors metallic surfaces, which are less active. The decrease of the reaction rate ensures an accumulation of $\mathrm{CO}$ on smoothed surfaces. This model[52] theoretically predicted a strong temperature dependency of the oscillations, with higher temperatures leading to much shorter periods. Corresponding TEM images of the Pt foil of identical locations before and after CO oxidation demonstrate the changes in the morphology of the surface and are presented in Figure S2. 

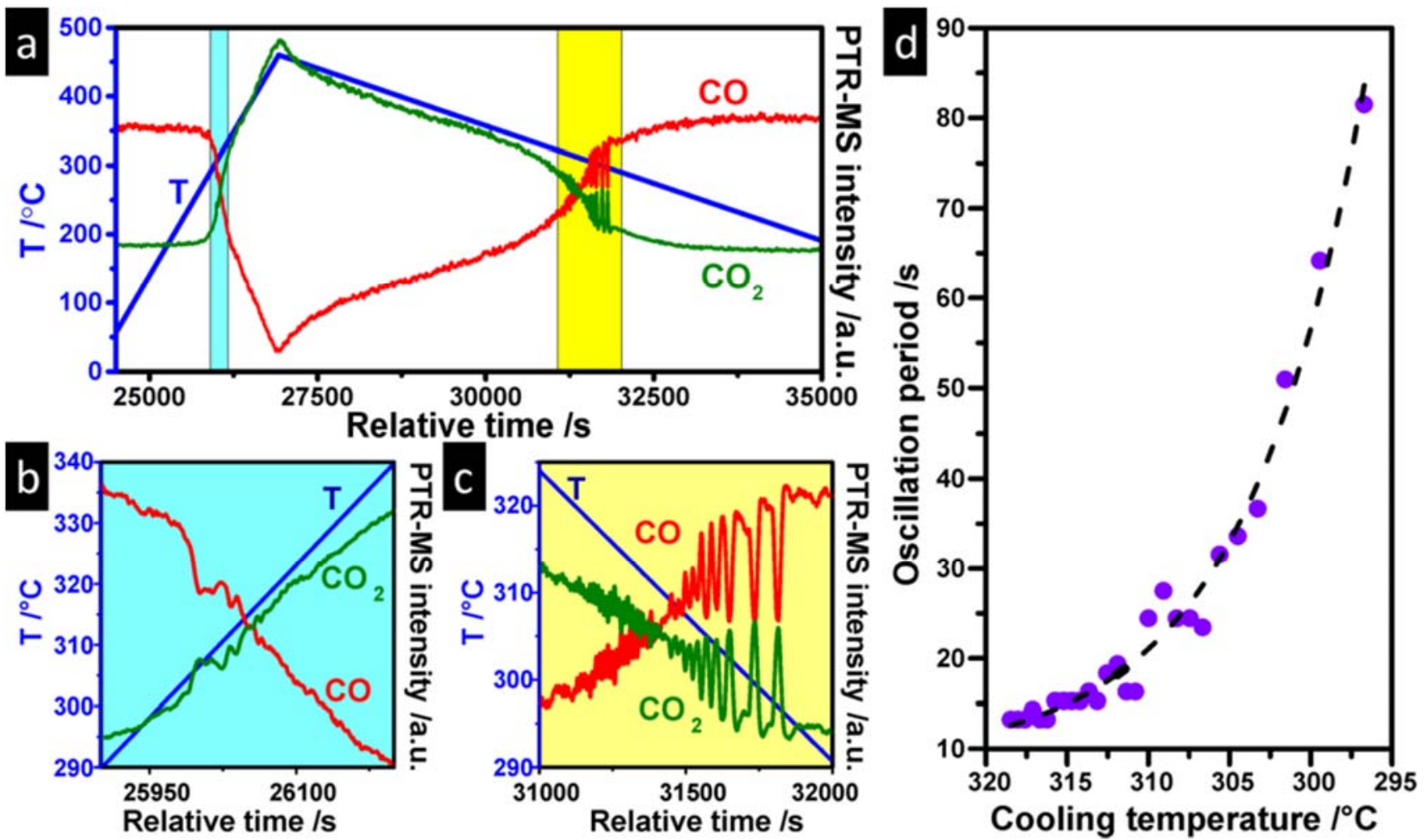

Figure 4: CO Oxidation of a Pt foil in the TEM grid reactor: (a) PTR-MS traces of $\mathrm{CO}$ and $\mathrm{CO}_{2}$; (b) magnified excerpt of the heating curve taken from the cyan region in (a); (c) close up of the yellow region from the cooling curve; (d) oscillation period versus cooling temperature. Conditions: $\mathrm{N}_{2}: 13.62$ $\mathrm{ml} / \mathrm{min}, \mathrm{O}_{2}: 1.15 \mathrm{ml} / \mathrm{min}, \mathrm{CO}: 0.23 \mathrm{ml} / \mathrm{min}$, heating rate: $10^{\circ} \mathrm{C} / \mathrm{min}$, cooling rate: $2^{\circ} \mathrm{C} / \mathrm{min}$.

\section{Identical Location Imaging (ILI)}

The morphological changes accompanying $\mathrm{CO}$ oxidation were investigated in further detail (Figure 5) using Pt nanoparticles. A light-off curve of Pt nanoparticles is presented in Figure 5a. The exposure of pristine $\mathrm{Si}_{3} \mathrm{~N}_{4}$ TEM grids to $\mathrm{CO}$ oxidation conditions evidences no catalytic conversion (Figure 5a, black curve) in the measured temperature regime, which demonstrates the inertness and cleanliness of the reactor setup. After the deposition of Pt nanoparticles on the TEM grid an increase of the $\mathrm{CO}_{2}$ traces (Figure 5a, green curve), which is accompanied by a decrease of the CO signal (Figure 5a, red curve), is 
detected by the PTR-MS at temperatures above $200^{\circ} \mathrm{C}$. After quenching the reaction, identical Pt nanoparticles were reinvestigated in the TEM. A detailed particle size distribution analysis (Figure 5b) suggests the transformation of spherical to more anisotropic particles. Figure 5c displays TEM images recorded at identical locations before (top) and after (bottom) the catalytic reaction. The images demonstrate the mobility of individual nanoparticles during the prevailing time of the catalytic reaction, which can be expressed by rotation, migration and reshaping.
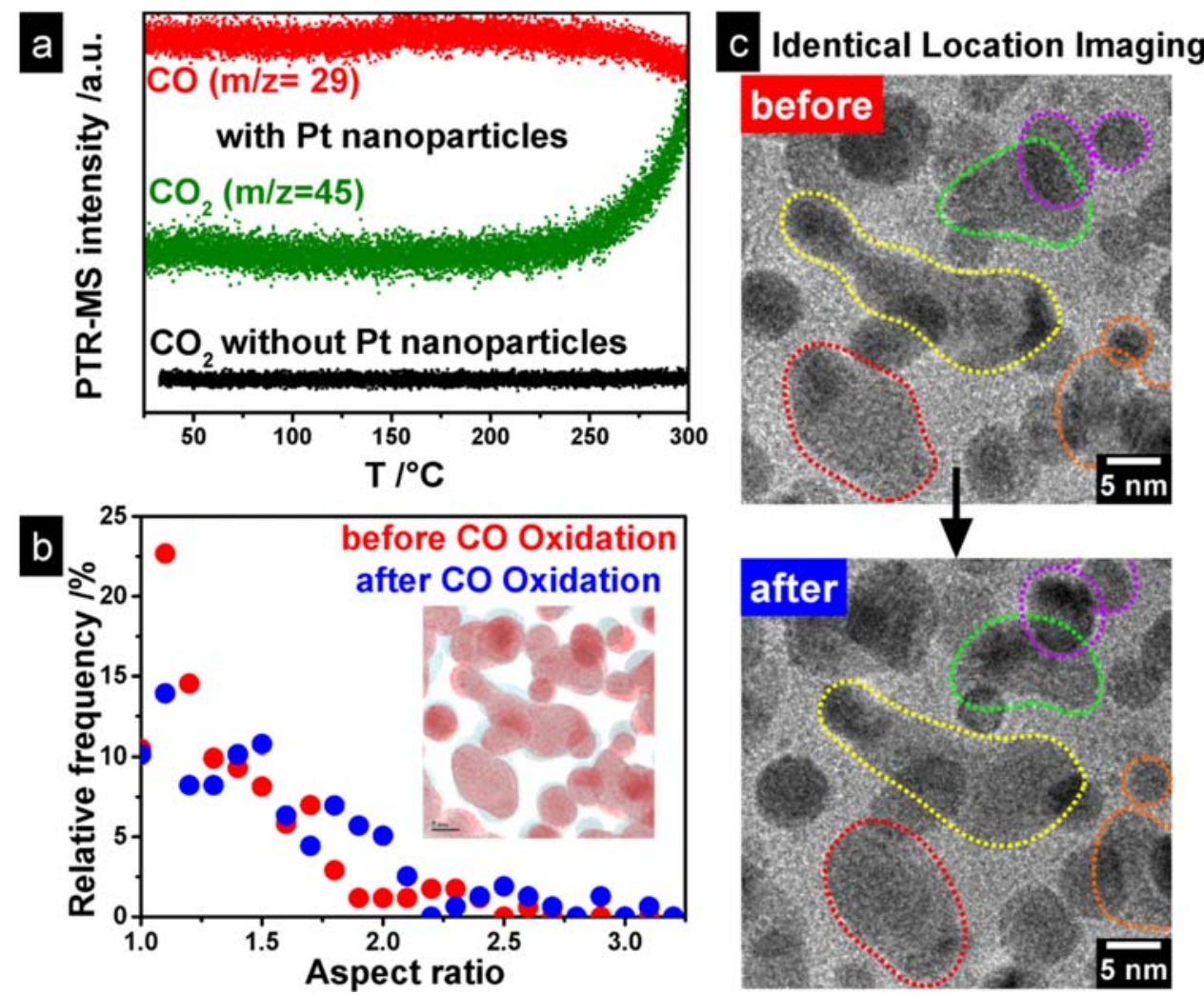

Figure 5. Identical location imaging of Pt nanoparticle in CO Oxidation: (a) PTR-MS traces and (b) statistical analysis of morphological changes of Pt nanoparticles before (red) and after (blue) $\mathrm{CO}$ oxidation. (c) Identical location imaging of Pt nanoparticles before (top) and after (bottom) $\mathrm{CO}$ oxidation. Colored contours highlight nanoparticles or nanoparticles arrangements that demonstrate 
pronounced structural changes or shifts. Conditions: $\mathrm{CO}: \mathrm{O}_{2}: \mathrm{N}_{2}=1: 5: 60$, ramp: $10^{\circ} \mathrm{C} / \mathrm{min}$, flow: $15 \mathrm{ml} / \mathrm{min}$.

\section{Sample Transfer and High Resolution Imaging}

As shown in Figure 6a-c the quasi in situ reshaping of nanoparticles can be tracked even at atomic resolution. Owing to the small volume of the TEM grid reactor the catalytic reaction can be instantly quenched at any time by simply switching off the laser. Thus, individual steps of restructuring can be imaged. The observed minute changes can be assigned to chemical potential induced structural adaption which can take place already at the early stages of $\mathrm{CO}$ oxidation (Figure $5 \mathrm{c}$ and $6 \mathrm{a}-\mathrm{c}$ ). In addition, the Pt nanoparticle highlighted in Figure 6c shows a 110 termination. In particular, this surface termination is prone for chemical potential induced reconstruction during $\mathrm{CO}$ oxidation. It has been demonstrated that after passing a certain threshold of $\mathrm{CO}$ consumption the remaining oxygen excess at the surface induces structural faceting of the termination.[7] As we performed ILI at low conversion and stoichiometric feed mixture (Figure S3) where still sufficient CO remains in the feed no changes of the 110 termination were observed.

In addition, often post-catalytic contact to ambient air may cause changes to the samples, which can be expressed by oxidation, hydration and/or electronic structure alterations. Therefore, a secure transfer system was established to avoid exposure to ambient air during transport of the sample from the TEM grid reactor to the TEM and back. The transfer system involves the use of automatic and hermetical sealed quick connectors mounted at the inlet and outlet of the reactor, the transient storage and transfer into an Ar-containing inert glove box and the use of vacuum transfer holders.[33] Imaging the $\mathrm{Cu} / \mathrm{ZnO} / \mathrm{Al}_{2} \mathrm{O}_{3}$ catalyst for methanol synthesis after reductive activation in hydrogen atmosphere at ambient pressure may act as an example. During this activation period the $\mathrm{Cu}^{2+}$ moieties, which are homogeneously distributed in the solid zincian malachite solution start to form individual, metallic $\mathrm{Cu}$ 
nanoparticles. These in situ generated $\mathrm{Cu}$ nanoparticles are supported and, due to the occurrence of strong metal support interaction (SMSI), embedded by a $\mathrm{ZnO}$ overlayer.[18] $\mathrm{Cu}$, however, is very sensitive to oxygen and immediately oxidizes even at room temperature at low oxygen partial pressure.[54-55] Figure 6d shows a high resolution TEM image of zincian malachite reduced in the TEM grid reactor at $350^{\circ} \mathrm{C}$. The sample was securely transferred via the outlined transfer system. Fast Fourier Transform (FFT) analysis evidences the presence of metallic $\mathrm{Cu}$ nanoparticle, which is embedded by an amorphous $\mathrm{ZnO}$ layer. The absence of the graphite-like structure of the $\mathrm{ZnO}$ overlayer can be attributed to the higher reduction temperature.
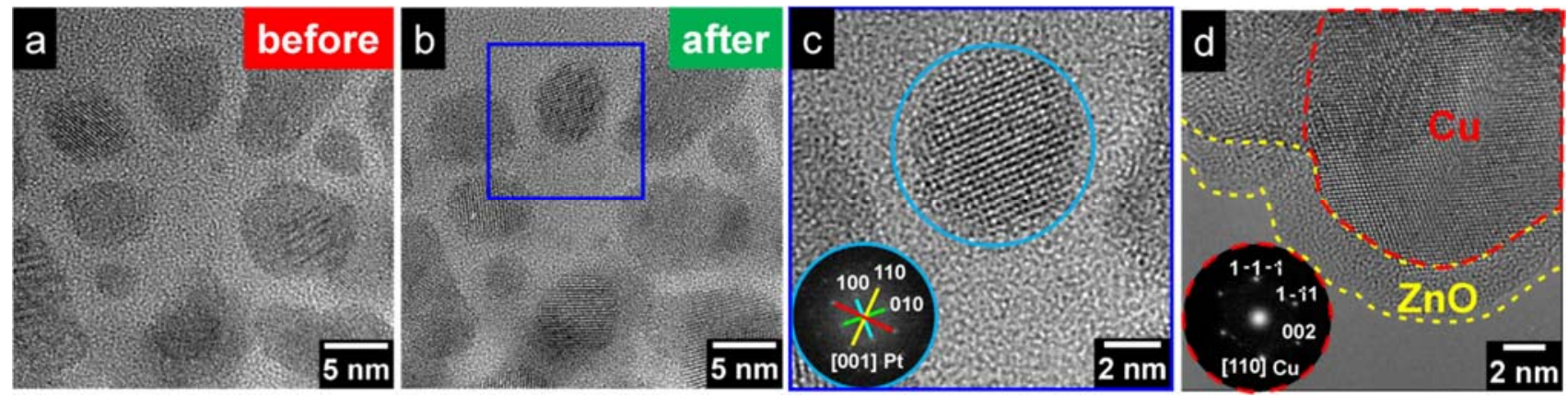

Figure 6. High resolution TEM images of Pt nanoparticles before (a) and after (b,c) CO oxidation (conditions: $\mathrm{CO}: \mathrm{O}_{2}: \mathrm{N}_{2}=2: 1: 60$, ramp: $10^{\circ} \mathrm{C} / \mathrm{min}$, flow: $15 \mathrm{ml} / \mathrm{min}$ ). (c) Magnified region of the Figure $6 \mathrm{~b}$, the Fast Fourier analysis (FFT, inset (c, bottom) was recorded from the blue highlighted Pt nanoparticle. (d) Inert sample transfer: high resolution TEM image of reduced $\mathrm{Cu} / \mathrm{ZnO} / \mathrm{Al}_{2} \mathrm{O}_{3}$ activated in hydrogen atmosphere at $350^{\circ} \mathrm{C}$ (conditions: $\mathrm{H}_{2} / \mathrm{N}_{2}=1 / 19$, heating rate: $10^{\circ} \mathrm{C} / \mathrm{min}$, dwell time: $2 \mathrm{~h}$, flow: $10 \mathrm{ml} / \mathrm{min}$ ); red: $\mathrm{Cu}$ and yellow: $\mathrm{ZnO}$.

\section{DISCUSSION AND CONCLUSION.}

As shown above, the presented TEM grid reactor allows the visual investigation of morphological changes of identical catalyst particles under quasi in situ conditions, i.e. decoupling the catalytic gas- 
phase reaction and TEM analysis. The system allows the detection of conversion of TEM amounts of sample and is robust to withstand different conditions and gas mixtures, ranging from reductive to oxidative. In addition, the different samples, which were investigated, display the broad versatility of this concept. The possibility to detect oscillation phenomena further indicates the fast response and read out time of the PTR-MS and shows the capability of our system to track kinetic phenomena.

Compared to usual imaging of random locations of materials that exhibit a statistical uncertainty, quasi in situ TEM imaging provides direct insight into the studied events. Quasi in situ TEM characterization features relevant, homogeneous reaction, and well-defined flow conditions for all catalyst particles and high-resolution TEM imaging. The introduced transfer system (reactor $\leftrightarrow$ glove box $\leftrightarrow$ vacuum transfer holder $\leftrightarrow$ TEM) allows a secure sample transfer and the avoidance of moisture and air-induced surface changes. In addition, the impact of the electron beam during the catalytic reaction, which is expressed by electron-sample and/or electron-gas interactions, can be minimalized by this concept. The minimization of the electron impact is of particular importance in heterogeneous catalysis. Usually, solid catalyst systems are highly energetic, metastable materials, which geometrically and/or electronically transform even by small external energy stimuli. In addition, gases may form reactive radical species while interacting with the electron beam and may, therefore, contribute to irrelevant catalytic conversion and/or structural changes. The TEM grid reactor concept may be limited by the absence of real-time information and may be prone to cooling and transfer artifacts, as well as wall reactions. As we have shown above, the latter can be avoided by careful passivating the inner parts of the reactor. Furthermore, the examination of thermal and gas phase induced alterations of nanoparticles requires suitable TEM supports, which are stable and non-reactive under the applied conditions.

Prospectively, the quasi in situ approach may complement ex situ and in situ TEM analysis in heterogeneous catalysis linking relevant reaction conditions, high resolution imaging, and detectable 
conversion with real time imaging. A relevant, overall and visual picture of structural alterations during heterogeneous catalysis can only be obtained, if quasi in situ and in situ TEM are applied on the same sample and the same conditions in a comprehensive fashion. Heterogeneous catalyst can be best compared, when they operate under steady state conditions. Thus, in particular for catalytic systems, for which the development of the steady state regime is a long-lasting process, the TEM grid reactor setup will be beneficial. The methanol synthesis over $\mathrm{Cu} / \mathrm{ZnO} / \mathrm{Al}_{2} \mathrm{O}_{3}$ catalysts may act as example.[17]

\section{AUTHOR CONTRIBUTIONS}

\$These authors contributed equally.

\section{ACKNOWLEDGEMENTS}

Julia Schumann and Malte Behrens are acknowledged for the preparation of $\mathrm{Cu} / \mathrm{ZnO} / \mathrm{Al}_{2} \mathrm{O}_{3}$ catalysts. The authors thank Ralf Krähnert for the calculation of the Reynold's numbers.

The authors thank the Max Planck Society for funding.

Declarations of interest: none.

\section{REFERENCES}

1. Olah, G. A.; Goeppert, A.; Prakash, G. K. S., Beyond oil and gas: the methanol economy. Wiley; 2009, ISBN: 9783527324224.

2. Schlögl, R., Chemical energy storage. De Gruyter; 2013, ISBN: 978-3-11-026632-0.

3. Schlögl, R., Heterogeneous catalysis. Angew. Chem., Int. Ed. 2015, 54 (11), 3465-3520, doi: 10.1002/anie.201410738.

4. Hävecker, M.; Mayer, R. W.; Knop-Gericke, A.; Bluhm, H.; Kleimenov, E.; Liskowski, A.; Su, D.; Follath, R.; Requejo, F. G.; Ogletree, D. F.; Salmeron, M.; Lopez-Sanchez, J. A.; Bartley, J. K.; Hutchings, G. J.; Schlögl, R., In situ investigation of the nature of the active surface of a vanadyl pyrophosphate catalyst during n-butane oxidation to maleic anhydride. J. Phys. Chem. B 2003, 107 (19), 4587-4596, doi: 10.1021/jp027259j.

5. Hävecker, M.; Wrabetz, S.; Kröhnert, J.; Csepei, L.-I.; Naumann d'Alnoncourt, R.; Kolen'ko, Y. V.; Girgsdies, F.; Schlögl, R.; Trunschke, A., Surface chemistry of phase-pure M1 MoVTeNb oxide during operation in selective oxidation of propane to acrylic acid. J. Catal. 2012, 285 (1), 48-60, doi: 10.1016/j.jcat.2011.09.012.

6. Trunschke, A.; Noack, J.; Trojanov, S.; Girgsdies, F.; Lunkenbein, T.; Pfeifer, V.; Hävecker, M.; Kube, P.; Sprung, C.; Rosowski, F.; Schlögl, R., The impact of the bulk structure on surface dynamics of complex Mo-Vbased oxide catalysts. ACS Catal. 2017, 7 (4), 3061-3071, doi: 10.1021/acscatal.7b00130. 
7. Vendelbo, S. B.; Elkjær, C. F.; Falsig, H.; Puspitasari, I.; Dona, P.; Mele, L.; Morana, B.; Nelissen, B. J.; van Rijn, R.; Creemer, J. F.; Kooyman, P. J.; Helveg, S., Visualization of oscillatory behaviour of Pt nanoparticles catalysing CO oxidation. Nat. Mater. 2014, 13 (9), 884-890, doi: 10.1038/nmat4033.

8. Bremmer, G. M.; Zacharaki, E.; Sjastad, A. O.; Navarro, V.; Frenken, J. W. M.; Kooyman, P. J., In situ TEM observation of the Boudouard reaction: multi-layered graphene formation from $\mathrm{CO}$ on cobalt nanoparticles at atmospheric pressure. Faraday Discuss. 2017, 197 (0), 337-351, doi: 10.1039/C6FD00185H.

9. Eren, B.; Heine, C.; Bluhm, H.; Somorjai, G. A.; Salmeron, M., Catalyst chemical state during CO oxidation reaction on $\mathrm{Cu}(111)$ studied with ambient-pressure X-ray photoelectron spectroscopy and near edge X-ray adsorption fine structure spectroscopy. J. Am. Chem. Soc. 2015, 137 (34), 11186-11190, doi: $10.1021 /$ jacs. 5 b07451.

10. Velasco-Velez, J. J.; Pfeifer, V.; Hävecker, M.; Weatherup, R. S.; Arrigo, R.; Chuang, C.-H.; Stotz, E.; Weinberg, G.; Salmeron, M.; Schlögl, R.; Knop-Gericke, A., Photoelectron spectroscopy at the graphene-liquid interface reveals the electronic structure of an electrodeposited cobalt/graphene electrocatalyst. Angew. Chem., Int. Ed. 2015, 54 (48), 14554-14558, doi: 10.1002/anie.201506044.

11. Burcham, L. J.; Deo, G.; Gao, X.; Wachs, I. E., In situ IR, Raman, and UV-Vis DRS spectroscopy of supported vanadium oxide catalysts during methanol oxidation. Top. Catal. 2000, 11 (1), 85-100, doi: 10.1023/a:1027275225668.

12. Pfeifer, V.; Jones, T. E.; Velasco Velez, J. J.; Massue, C.; Greiner, M. T.; Arrigo, R.; Teschner, D.; Girgsdies, F.; Scherzer, M.; Allan, J.; Hashagen, M.; Weinberg, G.; Piccinin, S.; Havecker, M.; Knop-Gericke, A.; Schlogl, R., The electronic structure of iridium oxide electrodes active in water splitting. Phys. Chem. Chem. Phys. 2016, 18 (4), 2292-2296, doi: 10.1039/C5CP06997A.

13. Pfeifer, V.; Jones, T. E.; Wrabetz, S.; Massue, C.; Velasco Velez, J. J.; Arrigo, R.; Scherzer, M.; Piccinin, S.; Havecker, M.; Knop-Gericke, A.; Schlogl, R., Reactive oxygen species in iridium-based OER catalysts. Chem. Sci. 2016, 7 (11), 6791-6795, doi: 10.1039/C6SC01860B.

14. Freakley, S. J.; He, Q.; Harrhy, J. H.; Lu, L.; Crole, D. A.; Morgan, D. J.; Ntainjua, E. N.; Edwards, J. K.; Carley, A. F.; Borisevich, A. Y.; Kiely, C. J.; Hutchings, G. J., Palladium-tin catalysts for the direct synthesis of $\mathrm{H}_{2} \mathrm{O}_{2}$ with high selectivity. Science 2016, 351 (6276), 965-968, doi: 10.1126/science.aad5705.

15. Nguyen, L.; Tao, F., Development of a reaction cell for in-situ/operando studies of surface of a catalyst under a reaction condition and during catalysis. Rev. Sci. Instrum. 2016, 87 (6), 064101, doi: 10.1063/1.4946877.

16. de Jonge, N.; Bigelow, W. C.; Veith, G. M., Atmospheric pressure scanning transmission electron microscopy. Nano Lett. 2010, 10 (3), 1028-1031, doi: 10.1021/n1904254g.

17. Lunkenbein, T.; Girgsdies, F.; Kandemir, T.; Thomas, N.; Behrens, M.; Schlögl, R.; Frei, E., Bridging the time gap: a copper/zinc oxide/aluminum oxide catalyst for methanol synthesis studied under industrially relevant conditions and time scales. Angew. Chem., Int. Ed. 2016, 55 (41), 12708-12712, doi: 10.1002/anie.201603368.

18. Lunkenbein, T.; Schumann, J.; Behrens, M.; Schlögl, R.; Willinger, M. G., Formation of a ZnO overlayer in industrial $\mathrm{Cu} / \mathrm{ZnO} / \mathrm{Al}_{2} \mathrm{O}_{3}$ catalysts induced by strong metal-support interactions. Angew. Chem., Int. Ed. 2015, 54 (15), 4544-4548, doi: 10.1002/anie.201411581.

19. Wang, Z.; Santhanagopalan, D.; Zhang, W.; Wang, F.; Xin, H. L.; He, K.; Li, J.; Dudney, N.; Meng, Y. S., In situ STEM-EELS observation of nanoscale interfacial phenomena in all-solid-state batteries. Nano Lett. 2016, 16 (6), 3760-3767, doi: 10.1021/acs.nanolett.6b01119.

20. Korup, O.; Goldsmith, C. F.; Weinberg, G.; Geske, M.; Kandemir, T.; Schlögl, R.; Horn, R., Catalytic partial oxidation of methane on platinum investigated by spatial reactor profiles, spatially resolved spectroscopy, and microkinetic modeling. J. Catal. 2013, 297, 1-16, doi: 10.1016/j.jcat.2012.08.022.

21. Korup, O.; Mavlyankariev, S.; Geske, M.; Goldsmith, C. F.; Horn, R., Measurement and analysis of spatial reactor profiles in high temperature catalysis research. Chem. Eng. Process. 2011, 50 (10), 998-1009, doi: 10.1016/j.cep.2011.05.024.

22. Ruska, E., Beitrag zur übermikroskopischen Abbildung bei höheren Drucken. Kolloid-Zeitschrift 1942, 100 (2), 212-219, doi: 10.1007/bf01519549.

23. Marton, L., Electron Microscopy of Biological Objects. Phys. Rev. 1934, 46 (6), 527-528, doi: 10.1103/PhysRev.46.527. 
24. Marton, L., La microscope electronique des objects biologiques. Acad. R. Belg. Bull. Cl. Sci. 1934, 5 (20), 439-446.

25. Hansen, T. W.; Wagner, J. B., Environmental transmission electron microscopy in an aberration-corrected environment. Microsc. Microanal. 2012, 18 (4), 684-690, doi: 10.1017/S1431927612000293.

26. Helveg, S.; Lopez-Cartes, C.; Sehested, J.; Hansen, P. L.; Clausen, B. S.; Rostrup-Nielsen, J. R.; AbildPedersen, F.; Norskov, J. K., Atomic-scale imaging of carbon nanofibre growth. Nature 2004, 427 (6973), 426429, doi: $10.1038 /$ nature 02278 .

27. Roiban, L.; Li, S.; Aouine, M.; Tuel, A.; Farrusseng, D.; Epicier, T., Fast 'Operando' electron nanotomography. J. Microsc. 2017, 117-126, doi: 10.1111/jmi.12557.

28. de Jonge, N.; Ross, F. M., Electron microscopy of specimens in liquid. Nat. Nanotechnol. 2011, 6 (11), 695704, doi: 10.1038/nnano.2011.161.

29. Hermannsdörfer, J.; de Jonge, N., Studying dynamic processes of nano-sized objects in liquid using scanning transmission electron microscopy. J. Vis. Exp. 2017, (120), 54943, doi: 10.3791/54943.

30. Elgrabli, D.; Dachraoui, W.; Ménard-Moyon, C.; Liu, X. J.; Bégin, D.; Bégin-Colin, S.; Bianco, A.; Gazeau, F.; Alloyeau, D., Carbon nanotube degradation in macrophages: Live nanoscale monitoring and understanding of biological pathway. ACS Nano 2015, 9 (10), 10113-10124, doi: 10.1021/acsnano.5b03708.

31. Raabe, S.; Mierwaldt, D.; Ciston, J.; Uijttewaal, M.; Stein, H.; Hoffmann, J.; Zhu, Y.; Blöchl, P.; Jooss, C., In situ electrochemical electron microscopy study of oxygen evolution activity of doped manganite perovskites. Adv. Funct. Mater. 2012, 22 (16), 3378-3388, doi: 10.1002/adfm.201103173.

32. Hansen, P. L.; Wagner, J. B.; Helveg, S.; Rostrup-Nielsen, J. R.; Clausen, B. S.; Topsøe, H., Atom-resolved imaging of dynamic shape changes in supported copper nanocrystals. Science 2002, 295 (5562), 2053-2055, doi: $10.1126 /$ science. 1069325

33. Kooyman, P. J.; Hensen, E. J. M.; de Jong, A. M.; Niemantsverdriet, J. W.; van Veen, J. A. R., The observation of nanometer-sized entities in sulphided Mo-based catalysts on various supports. Catal. Lett. 2001, 74 (1), 49-53, doi: 10.1023/a:1016632130625.

34. Damsgaard, C. D.; Zandbergen, H.; W. Hansen, T.; Chorkendorff, I.; B. Wagner, J., Controlled environment specimen transfer. Microsc. Microanal. 2014, 20 (4), 1038-1045, doi: 10.1017/S1431927614000853.

35. Malladi, S. R. K.; Tichelaar, F. D.; Xu, Q.; Wu, M. Y.; Terryn, H.; Mol, J. M. C.; Hannour, F.; Zandbergen, $\mathrm{H}$. W., Quasi in situ analytical TEM to investigate electrochemically induced microstructural changes in alloys: AA2024-T3 as an example. Corros. Sci. 2013, 69 (0), 221-225, doi: 10.1016/j.corsci.2012.12.006.

36. Mayrhofer, K. J. J.; Ashton, S. J.; Meier, J. C.; Wiberg, G. K. H.; Hanzlik, M.; Arenz, M., Non-destructive transmission electron microscopy study of catalyst degradation under electrochemical treatment. J. Power Sources 2008, 185 (2), 734-739, doi: 10.1016/j.jpowsour.2008.08.003.

37. Hodnik, N.; Zorko, M.; Bele, M.; Hočevar, S.; Gaberšček, M., Identical location scanning electron microscopy: a case study of electrochemical degradation of $\mathrm{PtNi}$ nanoparticles using a new nondestructive method. J. Phys. Chem. C 2012, 116 (40), 21326-21333, doi: 10.1021/jp303831c.

38. Schumann, J.; Lunkenbein, T.; Tarasov, A.; Thomas, N.; Schlögl, R.; Behrens, M., Synthesis and characterisation of a highly active $\mathrm{Cu} / \mathrm{ZnO}: \mathrm{Al}$ catalyst. ChemCatChem 2014, 6 (10), 2889-2897, doi: $10.1002 /$ cctc. 201402278 .

39. Lindinger, W.; Hansel, A.; Jordan, A., On-line monitoring of volatile organic compounds at pptv levels by means of proton-transfer-reaction mass spectrometry (PTR-MS) medical applications, food control and environmental research. I. J. Mass Spectrom. 1998, 173 (3), 191-241, doi: 10.1016/S0168-1176(97)00281-4.

40. Ellis, A. M.; Mayhew, C. A., Proton Transfer Reaction Mass Spectrometry: Principles and Applications. Wiley; 2013, ISBN: 9781118683576.

41. Beauchamp, J.; Herbig, J.; Dunk1, J.; Singer, W.; Hansel, A., On the performance of proton-transfer-reaction mass spectrometry for breath-relevant gas matrices. Meas. Sci. Technol. 2013, 24 (12), 125003, doi: 10.1088/0957-0233/24/12/125003.

42. Sarig, S.; Kahana, F., Thermal decomposition of basic lead carbonate. Thermochim. Acta 1976, 14 (3), $263-$ 268, doi: 10.1016/0040-6031(76)85003-4.

43. The Extraction of Nickel from its Ores by the Mond Process. Nature 1898, 59, 63, doi: 10.1038/059063a0. 
44. Brynestad, J., Iron and nickel carbonyl formation in steel pipes and its prevention literature survey. Oak Ridge National Laboratory; Oak Ridge, Tenn, 1976.

45. Lascelles, K.; Morgan, L. G.; Nicholls, D.; Beyersmann, D., Nickel Compounds. In Ullmann's Encyclopedia of Industrial Chemistry, 2005, doi: 10.1002/14356007.a17_235.pub2.

46. Wildermuth, E.; Stark, H.; Friedrich, G.; Ebenhöch, F. L.; Kühborth, B.; Silver, J.; Rituper, R., Iron Compounds. In Ullmann's Encyclopedia of Industrial Chemistry, 2000, doi: 10.1002/14356007.a14_591.

47. Klyushin, A. Y.; Greiner, M. T.; Huang, X.; Lunkenbein, T.; Li, X.; Timpe, O.; Friedrich, M.; Hävecker, M.; Knop-Gericke, A.; Schlögl, R., Is nanostructuring sufficient to get catalytically active Au? ACS Catal. 2016, 6 (5), 3372-3380, doi: 10.1021/acscatal.5b02631.

48. Langmuir, I., The mechanism of the catalytic action of platinum in the reactions $2 \mathrm{CO}+\mathrm{O}_{2}=2 \mathrm{CO}_{2}$ and $2 \mathrm{H}_{2}+$ $\mathrm{O}_{2}=2 \mathrm{H}_{2} \mathrm{O}$. T. Faraday Soc. 1922, 17 (0), 621-654, doi: 10.1039/TF9221700621.

49. Chapter 3 oscillatory behaviour in the oxidation of CO. In Studies in surface science and catalysis, Slin'ko, M. M.; Jaeger, N. I., Eds. Elsevier; 1994; Vol. 86, pp 47-120, doi: 10.1016/S0167-2991(08)61539-6.

50. Turner, J. E.; Sales, B. C.; Maple, M. B., Oscillatory oxidation of Co over a Pt catalyst. Surf. Sci. 1981, 103 (1), 54-74, doi: 10.1016/0039-6028(81)90099-6.

51. Jensen, R.; Andersen, T.; Nierhoff, A.; Pedersen, T.; Hansen, O.; Dahl, S.; Chorkendorff, I., Self-sustained carbon monoxide oxidation oscillations on size-selected platinum nanoparticles at atmospheric pressure. Phys. Chem. Chem. Phys. 2013, 15 (8), 2698-2702, doi: 10.1039/C2CP43684A.

52. Hendriksen, B. L. M.; Ackermann, M. D.; van Rijn, R.; Stoltz, D.; Popa, I.; Balmes, O.; Resta, A.; Wermeille, D.; Felici, R.; Ferrer, S.; FrenkenJoost, W. M., The role of steps in surface catalysis and reaction oscillations. Nat. Chem. 2010, 2 (9), 730-734, doi: 10.1038/nchem. 728.

53. Masliuk, L.; Heggen, M.; Noack, J.; Girgsdies, F.; Trunschke, A.; Hermann, K. E.; Willinger, M.-G.; Schloegl, R.; Lunkenbein, T., Structural Complexity in Heterogeneous Catalysis: Cataloging Local NanoStructures. J. Phys. Chem. C 2017, 121 (43), 24093-24103, doi: 10.1021/acs.jpcc.7b08333.

54. White, A. H.; Germer, L. H., The rate of oxidation of copper at room temperature. T. Electrochem. Soc. 1942, 81 (1), 305-319, doi: 10.1149/1.3071381.

55. Boggio, J. E., The room temperature oxidation of $\mathrm{Cu}$ (111): Pressure effects. J. Chem. Phys. 1979, 70 (11), 5054-5058, doi: 10.1063/1.437347. 